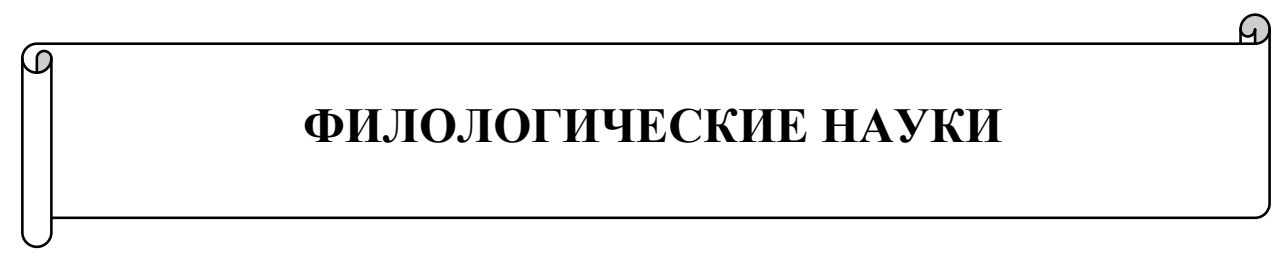

УДК [801.7:003.086]:[070:004.738.5]

DOI 10.37972/chgpu.2021.112.3.001

А. Д. Гаврилов

\begin{abstract}
СОПОСТАВИТЕЛЬНОЕ ИЗУЧЕНИЕ ПУНКТУАЦИИ В СЕТЕВОМ ГАЗЕТНОМ ЗАГОЛОВКЕ: К ПОСТАНОВКЕ ПРОБЛЕМЫ
\end{abstract}

\author{
Чувашский государственный университет имени И. Н. Ульянова, \\ 2. Чебоксары, Россия
}

\begin{abstract}
Аннотация. В статье поднимается проблема функционирования знаков препинания в русских, чувашских и английских медиатекстах на современном этапе. Автор утверждает, что анализ пунктуационного узуса необходимо проводить на материале сетевых газетных заголовков, поскольку в Интернете они являются главными речевыми единицами, формирующими информационную картину мира людей. Сетевые газетные заголовки концентрируют в себе языковые традиции и инновации, отражают тенденции пунктуационной практики цифрового общества, среди которых автор выделяет использование двоеточия в функции пояснения содержания, представленного в первой части бессоюзного сложного предложения, отсутствие вопросительного знака в конце вопросительного предложения, сочетание знаков препинания в предложении для усиления выразительности высказывания. Выявлено, что не все нормы и правила постановки знаков препинания рассматриваемых языков учитывают изменения в пунктуационном оформлении современных текстов. Автор приходит к выводу, что решение заявленной научной проблемы позволит уточнить новые функции и значения отдельных знаков препинания, переосмыслить их семантические и экспрессивные возможности, выявить национальные особенности и сформировать предложения для обновления свода правил пунктуации разноструктурных языков, а также внести существенный вклад в развитие теории медиа- и интернет-лингвистики, медиастилистики и, главным образом, сопоставительного языкознания.
\end{abstract}

Ключевые слова: сопоставительное языкознание, медиалингвистика, сетевой газетный заголовок, русская пунктуация, чувашская пунктуация, английская пунктуация.

A. D. Gavrilov

\title{
COMPARATIVE STUDY OF PUNCTUATION \\ IN AN ONLINE NEWSPAPER HEADLINE: STATEMENT OF THE PROBLEM
}

\section{Ulyanov Chuvash State University, Cheboksary, Russia}

Abstract. The article raises the problem of the functioning of punctuation marks in Russian, Chuvash and English media texts at the present stage. The author argues that punctuation usage should be 
analyzed on the material of online newspaper headlines since on the Internet they are the main speech units that form the information picture of the world. Online newspaper headlines concentrate language traditions and innovations, reflect the trends of punctuation practice of the developing digital society. Among them, the author highlights the use of the colon in the function of explaining the content presented in the first part of a non-union complex sentence, the absence of the question mark at the end of the question, the combination of punctuation marks in the sentence to enhance the expressiveness. It is revealed that not all the norms and rules of punctuation marks of the considered languages take into account changes in the punctuation design of modern texts. The author comes to the conclusion that the solution to the stated scientific problem will allow us to clarify the new functions and meanings of individual punctuation marks, to rethink their semantic and expressive possibilities, to identify the national features of their use, to form proposals for updating the punctuation rules of different structural languages and to make a significant contribution to the development of the theory of media and Internet linguistics, media stylistics and, mainly, comparative linguistics.

Keywords: comparative linguistics, media linguistics, online newspaper headline, Russian punctuation, Chuvash punctuation, English punctuation.

Введение. Одним из источников, отражающих современное состояние языка, сегодня являются медиатексты. Под данным термином мы понимаем журналистские тексты, функционирующие в медиапространстве: в прессе, на радио, телевидении и, что наиболее важно, в сети Интернет. Важно потому, что с развитием цифровых технологий и их доступностью сетевые медиатексты с каждым годом становятся все более востребованными массовой аудиторией и привлекательными для нее.

В последние два десятилетия формируется новая, цифровая культура коммуникации и потребления информации. Если в доинтернетное время образцом письменной речи являлись классические тексты (книги, журналы, газеты), то сейчас их место заняли сетевые тексты. Интернет теперь всегда «под рукой»: он конструирует не только информационную картину мира людей, но и создает новые языковые традиции.

С одной стороны, Интернет - новая коммуникационная среда, где тексты набираются и распространяются обычными пользователями в процессе общения. Если рассматривать такие речевые единицы, то они носят устно-письменный характер и перенимают особенности разговорного стиля. С другой стороны, Интернет - еще один источник поставки массовой информации, генерируемой профессиональными журналистами. Однако устройство онлайн-среды, формат взаимодействия с нею отличен от классических каналов, традиционных СМИ. Интернет работает в режиме реального времени, оперативно, здесь и сейчас, оттого и медиатексты в нем - стихийны, лаконичны и выразительны (чтобы выдержать конкуренцию, заинтересовать читателей и запомниться им). В нашем исследовании мы намерены заострить внимание на втором типе интернет-текстов - журналистских.

Цель данной работы - обозначить и актуализировать проблему изучения пунктуации в сетевом газетном заголовке в сопоставительном освещении на материале русского, чувашского и английского языков.

Актуальность исследуемой проблемы. Сетевые медиатексты, ориентируясь на массовую аудиторию и регулярно взаимодействуя с нею, фиксируют текущую речевую практику современников и одновременно формируют «языковой вкус эпохи». Цифровая трансформация и медиатизация различных сфер общественной жизни не проходит бесследно: она, как отмечает теоретик медиастилистики Н. И. Клушина, «приводит к становлению особого, медийного варианта литературного языка и способствует развитию национального стиля в целом» [5, с. 158]. Чтобы проследить динамику и направления развития языка, осмыслить его качественные изменения и актуальное словоупотребление, необходимо глубоко изучить особенности функционирования медиаречи в Интернете.

Материал и методы исследования. Данная работа основывается на описательноаналитическом методе. Наиболее подходящим материалом задуманного исследования, 
на наш взгляд, выступает сетевой газетный заголовок, поскольку именно он ориентирует пользователей в интернет-пространстве, а также, будучи созданным журналистами профессиональной редакции, пользуется авторитетом и вызывает доверие у читателей.

Результаты исследования и их обсуждение. Чтобы пробудить интерес и удержать внимание читателей, журналисты создают сетевые газетные заголовки, используя и расширяя репертуар лингвокреативных средств: обращаются к паремиологическим единицам, приемам экспрессивного синтаксиса, пунктуации и др. Так, в результате сопоставительного анализа синтаксических структур в позиции сетевого газетного заголовка на русском, чувашском и английском языках за 2019-2021 гг. нами обнаружено 6 ключевых моделей экспрессивных вопросительных конструкций (ЭВК): «1) ЭВК с вопросительным словом и без вопросительного знака; 2) ЭВК с вопросительным словом и вопросительным знаком; 3) ЭВК с двоеточием; 4) ЭВК в виде вопросно-ответной формы; 5) ЭВК с разделительным союзом “или”; 6) ЭВК с частицей “ли”» [3, с. 25]. Мы наблюдаем новые синтаксические схемы и пунктуационные рисунки предложений в позиции сетевого газетного заголовка. Они разрабатываются журналистами для получения экспрессивного эффекта и достижения прагматического воздействия, входят в узуальное использование и утверждаются в языке. Как справедливо замечает профессор Л. П. Крысин, «речевая практика может способствовать не только проникновению в нормированный язык новых для литературного языка единиц, но и укреплению в нем новых моделей - словообразовательных, синтаксических и др.» [6, с. 25]. Среди особенностей языка Интернета Н. И. Клушина выделяет «аграмматизм и пренебрежение пунктуацией» [5, с. 159].

Пунктуация - это не только система знаков препинания, но и свод правил их постановки. Она кодифицирована, носит нормативный характер. Так, нормы пунктуации русского языка были утверждены в 1956 году Академией наук СССР, Министерством высшего образования СССР и Министерством просвещения РСФСР. Однако с тех пор они неоднократно дополнялись и уточнялись в соответствии с современной практикой письма. Действующие нормы содержатся в книге «Правила русской орфографии и пунктуации. Полный академический справочник» [7]. Актуальные пунктуационные правила чувашского языка были утверждены 03 января 1991 года Научно-исследовательским институтом языка, литературы, истории и экономики при Совете министров Чувашской Республики. С того момента они не пересматривались и не дополнялись. Описаны в издании «Чувашская орфография и пунктуация (правила правильного написания)» [8]. Нормы пунктуации английского языка представлены в «Полной грамматике английского языка», впервые опубликованной в 1985 году [9]. Основы британского употребления знаков препинания приведены в справочнике «Новые правила Харта: Оксфордское руководство по стилистике» (2014 г.) [10]. Современные правила английской пунктуации на русском языке содержатся в пособии Н. Н. Гончаровой (2019 г.) [4].

Феномен пренебрежения правилами постановки знаков препинания в Интернете можно оценивать по-разному. Стоит заметить, что функционирование пунктуации в разных видах письменной речи - научной, официально-деловой, художественной и публицистической - всегда имело свою специфику. Журналисты нередко свободно и смело расставляют знаки препинания в своих текстах с целью придания дополнительных смыслов высказыванию и усиления его выразительности. Например, к числу современных тенденций пунктуационного оформления сетевых газетных заголовков можно отнести такие, как:

1) использование двоеточия в функции пояснения содержания, представленного в первой части бессоюзного сложного предложения:

- Однажды в Америке: как Дональд Трамп довел толпу до исступления (Известия, 07 января 2021);

- Сумки, часы, вино: во что инвестировать? (Ведомости, 05 июля 2021);

- A year of Covid: what have we learnt? / Год с ковидом: чему мы научились? / (The Times, 01 февраля 2021); 
2) отсутствие вопросительного знака в конце вопросительного предложения:

- Как агрохолдинги меняют сельское хозяйство (Ведомости, 22 января 2019);

- Что могут дать университеты регионам (Ведомости, 16 июля 2021);

- How to salvage children's wrecked education / Как спасти разрушенное образование детей / (The Times, 21 января 2021);

3) сочетание знаков препинания в предложении (тире + восклицательный знак, многоточие + восклицательный знак, двоеточие + восклицательный знак) как экспрессивный пунктуационный прием:

- Василий Чапаев миф мар - чӑнлӑх! / Василий Чапаев не миф - это реальность! / (Хыпар, 09 февраля 2018);

- Пыл вӑрланӑ... 440 банка! / Украли мед... 440 банок!/ (Хыпар, 11 декабря 2018);

- How to think positively: it helps! / Как мыслить позитивно: это помогает! / (The Times, 26 января 2021).

В результате, регулярно используя определенные пунктуационные приемы, журналисты таким образом невольно влияют на изменение устоявшихся правил и норм.

Сравнивая русскую пунктуацию XIX и XX веков, профессор Н. С. Валгина писала: «Изменения, которые произошли и постоянно происходят в пунктуации, касаются не только сужения или, наоборот, расширения функционального значения отдельных знаков, но и появления новых значений или утраты старых. Современную пунктуацию (в сравнении с пунктуацией XIX в.) отличает не столько качественное изменение знаков препинания, нормы их употребления (хотя и это, безусловно, есть), сколько новые общие тенденции пунктуационного оформления печатного текста, прямо отражающие синтаксические преобразования современного языка, которые проявляются, в частности, в активизации экспрессивных конструкций, в динамической ритмизации письменной речи в целом» [2, с. 434]. Так, одной из особенностей современного оформления сетевых газетных заголовков аналитических материалов качественных изданий является использование такого экспрессивного синтаксического приема, как парцелляция через многоточие:

- Чуна лӑпкать ... тасалӑх / Душу ласкает ... чистота / (Хыпар, 23 апреля 2018);

- С̧уралма та ... сывлӑх кирлӗ / Чтобы даже родиться ... нужно здоровье / (Хыпар, 19 ноября 2018);

- What I learnt ... hiring influencers / Что я усвоил ... нанимая инфлюенсеров / (The Times, 16 июля 2021);

- Escape to the country ... and the Hell's Angels / Сбежать в деревню ... и к «Ангелам Aда» / (The Times, 26 июля 2021).

В данных примерах многоточие усиливает выразительность экспрессивной парцеллированной конструкции не только за счет членения структуры и выделения логически значимой части высказывания, но и, как эмотивный знак, выполняет добавочную функцию выдержанной паузы, благодаря чему обращает на себя внимание читателей и вызывает у них эмоциональную реакцию. Стоит заметить, что многоточие стало активно использоваться в современных заголовках, особенно в заглавиях аналитических материалов, поскольку в них, в отличие от информационно-новостной журналистики, проявляется субъективный взгляд журналиста или героев его статьи. Многоточие позволяет передать определенное настроение, мнения, оценки, «кодировать эмоцию» [1, с. 18].

Проведя мониторинг сетевых версий качественных изданий на русском, чувашском и английском языках и собрав картотеку заглавий с многоточием за 2017-2021 гг., мы выявили некоторые национальные особенности употребления рассматриваемого знака препинания.

Так, в сетевых газетных заголовках на русском языке многоточие выполняет функцию незаконченности известного высказывания: 
- Пир во время... (Ведомости, 28 мая 2020);

- Ты виноват уж тем... (Известия, 13 января 2021).

Журналисты используют паремиологические единицы, так называемые прецедентные феномены, знакомые широкой аудитории, затем намеренно опускают одну или несколько лексем и ставят вместо них многоточие, чтобы читатель обратил внимание на известную фразу и мысленно произнес спрятанную за знаком препинания часть высказывания. Такой прием позволяет добиться прагматического эффекта.

В современных чувашеязычных заголовках многоточие используется в значении композиционной завязки истории. Этим журналист создает интригу и вызывает желание у читателей перейти по ссылке и узнать продолжение:

- Пурчче ал ӑсти ялта... / Жил в деревне умелеи... / (Хыпар, 04 сентября 2017);

- Перррехинче, Питравра... / Однажды, на Петров день... / (Хыпар, 26 февраля 2020).

Одна из функций употребления многоточия в сетевых заголовках на английском языке - это выражение иронии по отношению к сказанному. В этом значении мы обнаружили использование многоточия внутри синтаксической структуры:

- Making a fair algorithm is like trying to unboil an egg ... impossible / Создание справедливого алгоритма похоже на попытку сделать вареное яйцо сырым ... невозможно / (The Times, 17 августа 2020);

- Women reach 40 and hit their stride ... only to be cruelly shoved aside at work / Женщины достигают 40 лет и становятся мастерами своего дела ... только для того, чтобы их жестко подвинули на работе / (The Guardian, 07 апреля 2021).

В связи с вышеизложенным нам видится актуальным и необходимым обозначить и актуализировать проблему функционирования знаков препинания на современном этапе в активно развивающейся, но еще не изученной интернет-среде. В условиях медиацентризма общества наиболее иллюстративным материалом, как уже отмечалось выше, выступает сетевой газетный заголовок. Благодаря тому что он занимает стилистически сильную позицию в тексте, мы можем определить взаимосвязь современной пунктуационной практики с коммуникативными намерениями авторов. Кроме того, в условиях глобализации анализ пунктуационного оформления сетевых газетных заголовков полезно провести в сопоставительном аспекте и выявить национальные особенности функций и значений знаков препинания разных языков. Наибольший интерес для нас представляют русский, чувашский и английский языки. На сегодняшний день их пунктуация в сопоставлении друг с другом не изучена. Запланированное исследование позволит внести существенный вклад в развитие теории медиа- и интернет-лингвистики, медиастилистики и, главным образом, сопоставительного языкознания.

Выводы. Таким образом, лингвистические наблюдения над пунктуационным узусом в русско-, чуваше- и англоязычном сетевом газетном заголовке позволят:

1) уточнить современные практики использования знаков препинания в разных функциональных значениях в медиатекстах;

2) определить их стилистический, экспрессивный диапазон;

3) выявить национальные особенности пунктуации разноструктурных языков, обозначить межъязыковые сходства и различия.

Решение перечисленных задач - это возможность получить комплексное представление о современной пунктуации, проанализировать и переосмыслить функции и значения отдельных знаков препинания, их смысловые и экспрессивные возможности, а также обновить свод правил пунктуации разноструктурных национальных языков с учетом тенденций пунктуационного оформления текстов и языковых инноваций активно формирующегося цифрового общества. 


\section{ЛИТЕРАТУРА}

1. Будниченко Л. А., Вакку Г. В. Ресурсы экспрессии и интерпретация медиатекстов (к проблеме спецкурса по экспрессивной пунктуации) // Знак: проблемное поле медиаобразования. - 2019. - № 4(34). - С. 17-24.

2. Валгина Н. С. Синтаксис современного русского языка : учебник для вузов. - 2-е изд. - М. : Высшая школа, 1978. - $440 \mathrm{c}$.

3. Гаврилов А. Д. Вопросительная конструкция как синтаксическое средство выражения экспрессивности в сетевом газетном заголовке (на материале русского, чувашского и английского языков) // Вестник Чувашского государственного педагогического университета им. И. Я. Яковлева. - 2021. - № 1(110). - С. 18-27.

4. Гончарова Н. Н. Основы английской пунктуации: знаки препинания, небуквенные знаки, выделения. - М. : ЛЕНАНД, 2019. - 256 с.

5. Клушина Н. И. Медиастилистика и эмотивная лингвистика // Известия Волгоградского государственного педагогического университета. - 2019. - № 1(134). - С. 158-161.

6. Крысин Л. П. К соотношению системы языка, его нормы и узуса // Коммуникативные исследования. 2017. - № 2(12). - C. 20-31.

7. Правила русской орфографии и пунктуации. Полный академический справочник / под. ред. В. В. Лопатина. - М. : АСТ-ПРЕСС КНИГА, 2020. - 432 с.

8. Чӑваш орфографийӗпе пунктуацийӗ (тӗрӗс с̧ырмалли правилӑсем). - Шупашкар : Чӑваш кӗнеке издви, 1992. $-80 \mathrm{c}$.

9. A Comprehensive grammar of the English language / Randolph Quirk, Sidney Greenbaum, Geoffrey Leech, Jan Svartvik ; Ind. by David Crystal. - 4. impr. - London; New York : Longman, 1986. - 1779 p.

10. New Hart's rules: the Oxford style guide. $-2^{\text {nd }}$ ed. - Oxford univ. press, 2014. -415 p.

Статья поступила в редакцию 30.08 .2021

\section{REFERENCES}

1. Budnichenko L. A., Vakku G. V. Resursy ekspressii i interpretaciya mediatekstov (k probleme speckursa po ekspressivnoj punktuacii) // Znak: problemnoe pole mediaobrazovaniya. - 2019. - № 4(34). - S. 17-24.

2. Valgina N. S. Sintaksis sovremennogo russkogo yazyka : uchebnik dlya vuzov. - 2-e izd. - M. : Vysshaya shkola, 1978. $-440 \mathrm{~s}$.

3. Gavrilov A. D. Voprositel'naya konstrukciya kak sintaksicheskoe sredstvo vyrazheniya ekspressivnosti v setevom gazetnom zagolovke (na materiale russkogo, chuvashskogo i anglijskogo yazykov) // Vestnik Chuvashskogo gosudarstvennogo pedagogicheskogo universiteta im. I. Ya. Yakovleva. - 2021. - № 1(110). - S. 18-27.

4. Goncharova N. N. Osnovy anglijskoj punktuacii: znaki prepinaniya, nebukvennye znaki, vydeleniya. - M. : LENAND, 2019. $-256 \mathrm{~s}$

5. Klushina N. I. Mediastilistika i emotivnaya lingvistika // Izvestiya Volgogradskogo gosudarstvennogo pedagogicheskogo universiteta. - 2019. - № 1(134). - S. 158-161.

6. Krysin L. P. K sootnosheniyu sistemy yazyka, ego normy i uzusa // Kommunikativnye issledovaniya. 2017. - № 2(12). - S. 20-31.

7. Pravila russkoj orfografii i punktuacii. Polnyj akademicheskij spravochnik / pod. red. V. V. Lopatina. - M. : AST-PRESS KNIGA, 2020. - $432 \mathrm{~s}$. 1992. $-80 \mathrm{~s}$

8. Chăvash orfografijĕpe punktuacijĕ (tĕrĕs çyrmalli pravilăsem). - Shupashkar : Chăvash kĕneke izd-vi,

9. A Comprehensive grammar of the English language / Randolph Quirk, Sidney Greenbaum, Geoffrey Leech, Jan Svartvik ; Ind. by David Crystal. - 4. impr. - London; New York : Longman, 1986. - 1779 p.

10. New Hart's rules: the Oxford style guide. - 2nd ed. - Oxford univ. press, 2014. -415 p.

The article was contributed on August 30, 2021

\section{Сведения об авторе}

Гаврилов Артем Дмитриевич - аспирант кафедры чувашской филологии и культуры Чувашского государственного университета имени И. Н. Ульянова, г. Чебоксары, Россия; e-mail: artmaster28@rambler.ru

\section{Author information}

Gavrilov, Artem Dmitrievich - Post-graduate Student, Department of Chuvash Philology and Culture, I. Ulyanov Chuvash State University, Cheboksary, Russia; e-mail: artmaster28@rambler.ru 